\title{
Brain-Derived Neurotrophic Factor Promotes the Maturation of GABAergic Mechanisms in Cultured Hippocampal Neurons
}

\author{
Maki K. Yamada, ${ }^{*}$ Kohsuke Nakanishi, ${ }^{*}$ Shizu Ohba, Takeshi Nakamura, Yuji Ikegaya, Nobuyoshi Nishiyama, \\ and Norio Matsuki \\ Laboratory of Chemical Pharmacology, Graduate School of Pharmaceutical Sciences, The University of Tokyo, 7-3-1 \\ Hongo, Bunkyo-ku, Tokyo 113-0033, Japan
}

Brain-derived neurotrophic factor (BDNF) has been implicated in activity-dependent plasticity of neuronal function and network arrangement. To clarify how BDNF exerts its action, we evaluated the physiological, histological, and biochemical characteristics of cultured hippocampal neurons after long-term treatment with BDNF. Here we show that BDNF facilitates high $\mathrm{K}^{+}$-elicited release of GABA but not of glutamate and induces an increase in immunoreactive signals of glutamic acid decarboxylase, a GABA-synthesizing enzyme. The soma size of GABAergic neurons was enlarged in BDNF-treated cultures, whereas the average soma size of all neurons was virtually unchanged. BDNF also upregulated protein levels of $\mathrm{GABA}_{\mathrm{A}}$ receptors but not of glutamate receptors. These data imply that BDNF selectively advances the maturation of GABAergic syn- apses. However, immunocytochemical analyses revealed that a significant expression of TrkB, a high-affinity receptor for BDNF, was detected in non-GABAergic as well as GABAergic neurons. BDNF also increased to total amount of synaptic vesicleassociated proteins without affecting the number of presynaptic vesicles that can be labeled with $\mathrm{FM1}-43$ after $\mathrm{K}^{+}$depolarization. Together, our findings indicate that BDNF principally promotes GABAergic maturation but may also potentially contribute to excitatory synapse development via increasing resting synaptic vesicles.

Key word: BDNF; hippocampus; plasticity; neural network; GABA; inhibitory neuron; resting pool; synaptic vesicle-associated protein
Brain-derived neurotrophic factor (BDNF), a member of the neurotrophin family abundantly expressed in the CNS (Lewin and Barde, 1996), plays a crucial role in activity-dependent plastic changes in synaptic strength and network refinement. For instance, BDNF is reported to participate in the induction of long-term potentiation (Thoenen, 1995; Lu and Figurov, 1997) and long-term depression (Ikegaya et al., 2002) of synaptic transmission and is also implicated in the modification of neural circuits, including ocular dominance columns (Cabelli et al., 1995; Huang et al., 1999; Lein and Shatz, 2000). However, these two phenomena may involve distinct mechanisms (Mataga et al., 2001; Renger et al., 2002). The contribution of BDNF to epilepsy is well documented but contains partially controversial arguments (Binder et al., 2001; Reibel et al., 2001). Long-term infusion of BDNF prevents the development of kindling (Larmet et al., 1995), whereas blockade of endogenous BDNF also inhibits it (Binder et al., 1999). Therefore, to clarify the precise mechanisms underlying physiological and pathological reorganization and functional plasticity of neural networks, the long-term effect of BDNF should be investigated in simplified experimental systems.

We have focused the present study on the long-term effect of brain-derived neurotrophic factor (BDNF) on neuronal functions, and we provide a large body of evidence that BDNF

\footnotetext{
Received March 19, 2002; revised May 1, 2002; accepted May 29, 2002.

This work was supported by grants from the Ministry of Education, Culture, Sports, Science, and Technology.

*M.K.Y. and K.N. contributed equally to this work.

Correspondence should be addressed to Dr. Maki K. Yamada, Laboratory of Chemical Pharmacology, Graduate School of Pharmaceutical Sciences, The University of Tokyo, 7-3-1 Hongo, Bunkyo-ku, Tokyo 113-0033, Japan. E-mail: maki@mol.f.u-tokyo.ac.jp.

Copyright (C) 2001 Society for Neuroscience $\quad 0270-6474 / 01 / 227580-06 \$ 15.00 / 0$
}

primarily promotes GABAergic maturation. BDNF induces an enlargement of the soma of GABAergic neurons, increases the expression of $\mathrm{GABA}_{\mathrm{A}}$ receptor subunits and glutamic acid decarboxylase (GAD; a GABA-synthesizing enzyme), and facilitates high $\mathrm{K}^{+}$-elicited release of GABA. In addition to other studies that assessed the BDNF effects on synaptic vesicles (Pozzo-Miller et al., 1999; Collin et al., 2001; Tyler and Pozzo-Miller, 2001), our study has shown for the first time that BDNF dramatically upregulates the expression level of presynaptic vesicle-associated proteins without apparent changes in the active pool of synaptic vesicles, suggesting that BDNF induces an increase in resting synaptic vesicles. Taken together, our findings indicate that BDNF principally promotes GABAergic maturation but may also potentially contribute to excitatory synapse development via increasing resting synaptic vesicles.

\section{MATERIALS AND METHODS}

Primary culture. Cultured hippocampal neurons were prepared as described previously (Shitaka et al., 1996), with some modifications. Briefly, whole brains were isolated from embryonic day 18 Wistar rats, and the hippocampi were dissected out and treated with $0.25 \%$ trypsin (Difco Laboratories, Detroit, MI) and $0.01 \%$ deoxyribonuclease I (Sigma, St. Louis, MO) at $37^{\circ} \mathrm{C}$ for $30 \mathrm{~min}$. The cells were suspended with Neurobasal medium containing 10\% fetal bovine serum (Sanko-junyaku, Tokyo, Japan), and plated at a density of $65,000 \mathrm{cells} / \mathrm{cm}^{2}$ on polyethyleneimine (Sigma)-coated 24- or 48-well plates (Costar, Cambridge, MA), 35 $\mathrm{mm}$ dishes (Costar), and glass coverslips with flexiPERM (Sartorius, Goettingen, Germany). Twenty-four hours after plating, the medium was changed to serum-free Neurobasal medium with $2 \%$ B27 supplement (Life Technologies, Gaithersburg, MD) and $50 \mathrm{ng} / \mathrm{ml}$ BDNF (recombinant human BDNF, a gift from Sumitomo Pharmaceuticals, Osaka, Japan), and then the cultures were kept for the next 6-10 d in vitro.

Determination of glutamate and GABA release. Quantification of amino acid release was performed as described previously (Jeftinija et al., 1996), 
with some modifications. Briefly, cultured cells were washed five times with Krebs'-Ringer's solution (in mM: $130 \mathrm{NaCl}, 3 \mathrm{KCl}, 2 \mathrm{CaCl}_{2}, 0.8$ $\mathrm{MgSO}_{4}, 20$ HEPES, and 10 glucose) adjusted to $\mathrm{pH} 7.4$ with $\mathrm{NaOH}$. Depolarizing Krebs'-Ringer's solution containing $50 \mathrm{~mm} \mathrm{KCl}$ was applied for $1 \mathrm{~min}$ and collected into tubes on ice. All the assay buffer and culture plates were kept at $37^{\circ} \mathrm{C}$ during the manipulations. The samples were mixed with $o$-phthalaldehyde (Sigma) and reacted for $1 \mathrm{~min}$. The content of the derivatized amino acids was determined by an HPLC equipped with the reverse-phase capillary column C-18 (5 $\mu \mathrm{m}$; BAS Co. Ltd., Tokyo, Japan) and the fluorescence detector CMA280 (excitation at $340 \mathrm{~nm}$, emission at $445 \mathrm{~nm})(\mathrm{CMA} /$ Microdialysis, Stockholm, Sweden) (Lindroth and Mopper, 1979). The mobile (60 $\mu \mathrm{l} / \mathrm{min})$ solution consisting of (in mM) $100 \mathrm{KH}_{2} \mathrm{PO}_{4}, 100 \mathrm{Na}_{2} \mathrm{HPO}_{4}$, and 0.1 EDTA, pH 6.0 , contained $10 \%$ acetonitrile and $3 \%$ tetrahydrof uran. The peak area at the predicted position was calibrated against the standard curves for quantification with CMA200 software (CMA/Microdialysis).

Immunocytochemistry. Cells were fixed with $4 \%$ paraformaldehyde at $4^{\circ} \mathrm{C}$ for $30 \mathrm{~min}$. After treatment with $0.1 \%$ Triton X-100 in PBS for 15 min, they were incubated in 1-2\% serum-PBS for $1 \mathrm{hr}$, then with a primary antibody anti-GAD (anti-GAD for both 65 and $67 \mathrm{kDa}$; rabbit, 1:4000; AB1511 from Chemicon, Temecula, CA) or anti-GABA (rabbit, 1:5000; Sigma) and anti-TrkB (specific for full-length TrkB; gp145, goat, 1:1000; Santa Cruz Biotechnology, Santa Cruz, CA) overnight at $4^{\circ} \mathrm{C}$. After washes, cells were incubated with fluorochrome-conjugated antibody (FITC-anti-rabbit IgG from Sigma or Alexa flour 488 donkey anti-goat IgG and Alexa flour 594 donkey anti-rabbit IgG from Molecular Probes, Eugene, OR), 1:1000 for $1 \mathrm{hr}$ at room temperature. Fluorescence images were obtained with the confocal microscope LSM510 (Carl Zeiss, Jena, Germany) equipped with a differential interference contrast (DIC)-microscope and processed in the range in which negative controls showed no visible signals. For quantification of GAD, the 8-bit images were collected with the laser confocal microscope MRC-1000 (Bio-Rad Microscience Division, Cambridge, MA). Ten fields $\left(211 \times 317 \mu \mathrm{m}^{2}\right)$ from each well were randomly selected; the average of the overall fluorescence intensity values $(0-255)$ was calculated using LaserSharp imaging software (Bio-Rad) and normalized to the control value for each experiment. Results were obtained from 15 wells in five independent experiments.

Cell count and measurement of soma size. Cells were immunostained for microtubule-associated protein-2 (MAP-2) (1:4000 mouse; Boehringer Mannheim Biochemica, Mannheim, Germany) or GABA with Vectastain ABC elite kit (1:200 for secondary antibody; Vector Laboratories, Burlingame, CA). For cell count, the number of immunopositive neurons was counted in 10 randomly chosen areas $\left(1 \mathrm{~mm}^{2}\right)$ of each well under a bright-field microscope. Data were obtained from five wells from three independent experiments. For measurement of the soma area, transmitted-light images $\left(211 \times 317 \mu \mathrm{m}^{2}\right)$ were randomly obtained with the confocal microscope MRC-1000 (Bio-Rad), and the soma edge of all fully included positive cells was manually determined as a polygonal form. The surrounded areas were measured using LaserSharp imaging software (Bio-Rad). Data were collected from four frames in 11 wells for GABA and from one frame in three wells for MAP-2 in three independent experiments

Western blotting. Cells were washed with PBS and collected with a cell scraper. The cell suspension in traces of PBS was homogenized on ice and centrifuged at $750 \times g$ at $4^{\circ} \mathrm{C}$ for $5 \mathrm{~min}$ to remove the nucleus. The equal aliquots of the supernatants were separated by SDS-PAGE gel and transferred onto polyvinylidene difluoride membranes. The membrane was incubated in PBS containing $0.05 \%$ Tween 20 and $5 \%$ nonfat dry milk for $1 \mathrm{hr}$ and then exposed to a primary antibody against synaptophysin (1:200, mouse; Boehringer Mannheim Biochemica), synaptobrevin (1:500, rabbit; Wako, Osaka, Japan), syntaxin (1:300, mouse; Wako), GluR1 (1:300, rabbit; Chemicon), NR1 (1:300, rabbit; Chemicon), or $\mathrm{GABA}_{\mathrm{A}} \mathrm{R} \beta 2 / 3$ (only the $\beta 3$ subunit was detected in our culture; 1:300, mouse; Upstate Biotechnology, New York, NY) in $0.05 \%$ Tween $20-$ PBS at $4^{\circ} \mathrm{C}$ overnight and then to horseradish peroxidase-conjugated secondary antibody for appropriate IgG. Immunoreactive protein bands were detected by enhanced chemiluminescence using Renaissance (NEN, Boston, MA). The signals on Hyperfilm ECL (Amersham, Buckinghamshire, UK) were digitized and quantified using the software Scion Image (Scion Corporation, Frederick, MD). Protein levels were normalized with blots of $\beta$-actin on the same filters. Using serial dilution of samples, we confirmed that the signals were within the linear range of response under these conditions.

FM1-43 (Molecular Probes) imaging was performed as described pre-

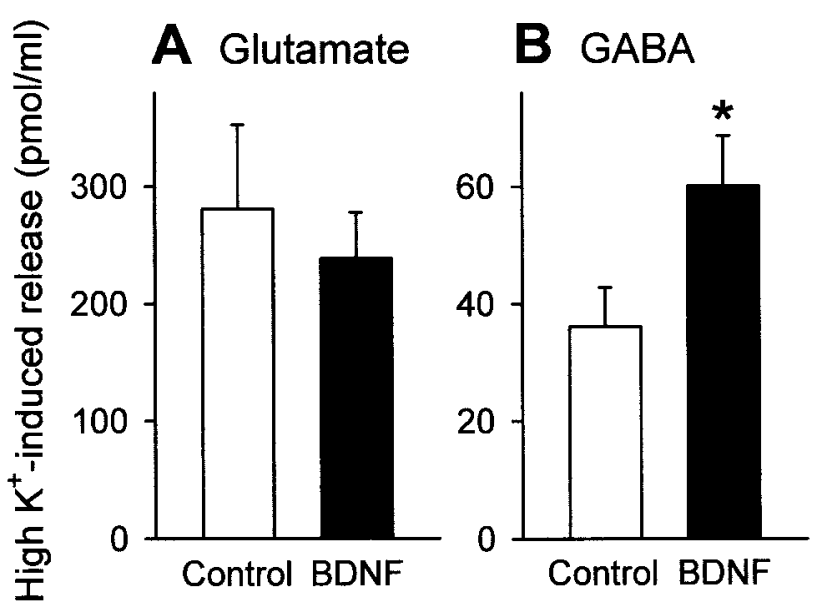

Figure 1. BDNF enhances high $\mathrm{K}^{+}$-evoked GABA release from cultured hippocampal neurons. After long-term treatment with $50 \mathrm{ng} / \mathrm{ml}$ BDNF from 1 to $7-11 \mathrm{~d}$ in vitro, cultures were stimulated by $\mathrm{K}^{+}$depolarization $(50 \mathrm{mM}, 1 \mathrm{~min})$, and the amount of released glutamate $(A)$ and GABA $(B)$ was quantified by HPLC. BDNF enhances high $\mathrm{K}^{+}$-evoked release of GABA but not of glutamate. Data are means \pm SEM of seven wells. ${ }^{*} p<0.05$ versus control, Student's $t$ test.

viously (Ikegaya et al., 2000b), with some modifications. The cultured cells were loaded with the fluorescence probe FM1-43 $(10 \mu \mathrm{M})$ by a $1 \mathrm{~min}$ stimulus of depolarization $(25 \mathrm{~mm} \mathrm{KCl})$, and then washed gently three times. Under the transmitted light, the frames were carefully chosen to include nearly the same number of cell bodies. Immediately $(<5 \mathrm{~min})$ after loading, FM1-43 fluorescence images were obtained with the confocal microscope MRC-1000 (Bio-Rad). At first, the fluorescence remaining after the second depolarizing stimulus ( $45 \mathrm{~mm} \mathrm{KCl}$ for $1 \mathrm{~min}$ ) was subtracted as baseline, nonsynaptic endocytosis, but that was proven to be negligible. Thus, four images $\left(211 \times 317 \mu \mathrm{m}^{2}\right)$ per well were randomly collected without subtraction, and the mean value of whole fluorescence intensity was normalized to the control value for each experiment. The background fluorescence could be set to produce no significant noise to the mean values.

\section{RESULTS}

\section{Brain-derived neurotrophic factor alters parameters of GABAergic synapses in cultured hippocampal neurons}

After hippocampal neurons were cultured in the continuous presence of $50 \mathrm{ng} / \mathrm{ml} \mathrm{BDNF}$ from 1- to 7-11 d in vitro, they were briefly stimulated at a high concentration of $\mathrm{K}^{+}(50 \mathrm{~mm}$ for 60 sec), and the amount of glutamate and GABA released into the media was assessed by HPLC. BDNF-treated cultures displayed a higher degree of GABA release, whereas glutamate release was virtually unchanged (Fig. 1).

To determine whether BDNF activates GABA synthesis, expression of the GABA-synthesizing enzyme GAD was explored by immunocytochemical staining with anti-GAD65/67 antibody. In untreated, control neurons, GAD immunoreactivity was detectable in some neurons, but its intensity was relatively low on average (Fig. $2 B$ ). In cultures exposed to BDNF for $7 \mathrm{~d}$, however, the signal was more evident (Fig. 2D). Quantitative analyses indicated that the mean signal intensity was increased more than twofold after BDNF treatment (Fig. 2E). Thus, the upregulation of GABA release may be attributable, at least in part, to elevated GABA synthesis. These results suggest that presynaptic GABAergic neurons are a target of the BDNF action.

BDNF has been shown to promote neuronal survival (Lowenstein and Arenault, 1996) and the differentiation of neuronal stem cells in hippocampal cultures (Vicario-Abejon et al., 2000). To confirm that the selective effect of BDNF on GABAergic neurons 
Figure 2. BDNF treatment induces an increase of the level of GAD expression. $A-D$, Representative images of cultures kept in the absence $(A, B)$ or presence $(C, D)$ of $50 \mathrm{ng} / \mathrm{ml} \mathrm{BDNF}$ for $7 \mathrm{~d}$. Cultures were immunostained with anti-GAD65/67. DIC images $(A, C)$ were obtained from the same microscopic fields of view as anti-GAD images $(B, D)$. "Hotter" colors in $B$ and $D$ correspond to higher immunoreactivity for GAD on an arbitrary pseudocolor scale. Scale bar, $20 \mu \mathrm{m}$. E, Quantification of GAD-immunopositive signal. The mean fluorescence intensity of 10 frames per well was normalized to the control. BDNF induced a significant increase in GAD immunoreactivity. Data are means $\pm \operatorname{SEM}(n=15) .{ }^{* *} p<0.01$ versus control, Student's $t$ test.
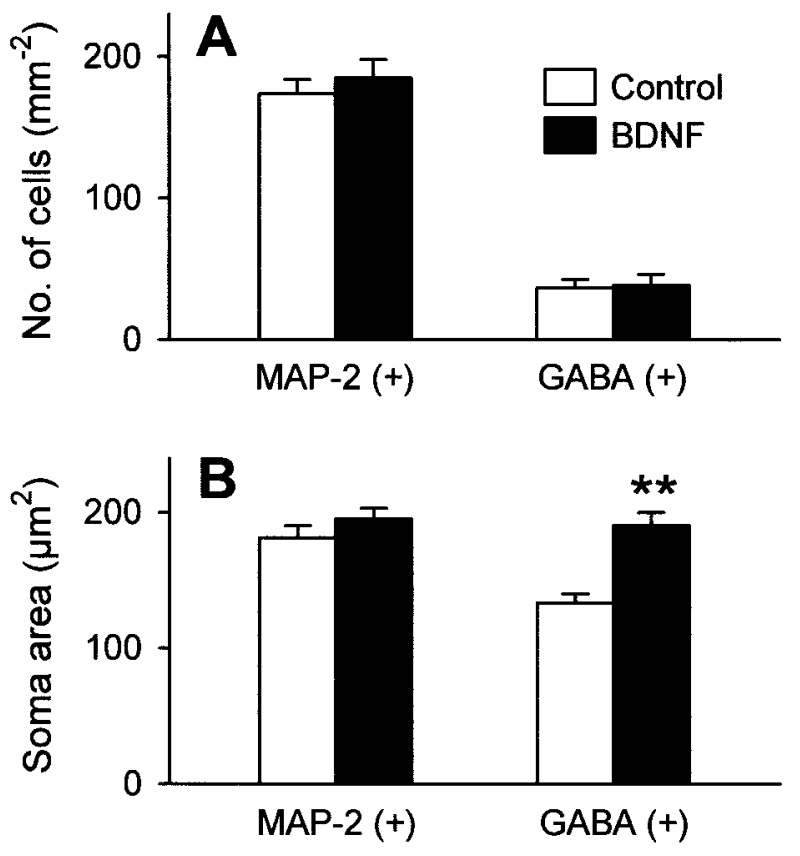

Figure 3. BDNF-treated GABAergic neurons possessed the enlarged soma. Neurons were cultured in the presence or absence of $50 \mathrm{ng} / \mathrm{ml}$ BDNF for $7-10 \mathrm{~d}$ and immunostained with anti-MAP-2 or anti-GABA antibody. $A$, Lack of the effect of BDNF on the survival of MAP-2- or GABA-positive cells. Data are means $\pm \operatorname{SEM}(n=5) . B$, The soma area of each cell was quantified. GABA-positive cells are enlarged in size after BDNF treatment. Data are means \pm SEM of $24-38$ cells. ${ }^{* *} p<0.01$ versus control, Student's $t$ test.

is not a misinterpretation resulting from a possible alteration in the number of surviving neurons, cultures were immunostained for MAP-2, a pan-neuronal marker, and GABA. In our cultures, BDNF had no apparent influence on survival of MAP-2- or GABA-positive neurons (Fig. 3A). Interestingly, however, we noticed that BDNF-treated cultures contained GABAergic neurons with enlarged somata. The average soma size of GABApositive, but not MAP-2-positive, neurons was significantly larger
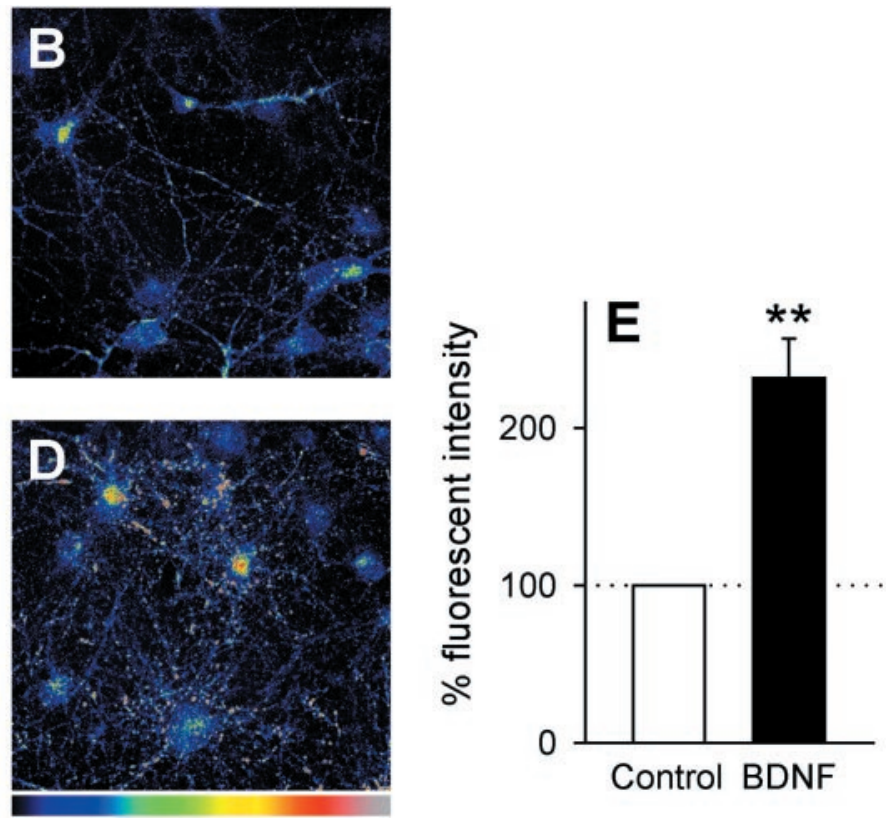

after BDNF treatment (Fig. 3B). Because a positive relationship between transcriptional activity and cell size is shown in neuronal and non-neuronal cells (Sato et al., 1994; Schmidt and Schibler, 1995), this observation is in accordance with BDNF-induced GAD upregulation. Although GABAergic neurons are also positive for MAP-2 immunostaining, this small part of neurons did not significantly contribute to the average soma size of total neurons. Indeed, in our cultures GABA-positive neurons were only $\sim 20 \%$ (Fig. $3 A$ ).

We assumed that a lack of effect of BDNF on non-GABAergic cells is attributable to little or no expression of TrkB, a highaffinity receptor for BDNF. To address this possibility, cultures were immunolabeled with anti-TrkB. Unexpectedly, an equivalent level of TrkB immunoreactivity was detected in almost all neurons; that is, both GABAergic and non-GABAergic cells (Fig. 4). More than $90 \%$ of MAP-2-positive neurons were immunostained with anti-TrkB, but GFAP-positive astroglial cells were negative (data not shown). These results suggest that nonGABAergic neurons are also a possible site of action of BDNF.

Therefore, we next tried to determine whether BDNF affects protein levels of glutamatergic receptors. Western blot analyses revealed no changes in the levels of the AMPA receptor subunit GluR1 or the NMDA receptor subunit NR1 (Fig. $5 A$ ). On the other hand, expression of the $\mathrm{GABA}_{\mathrm{A}}$ receptor subunit $\mathrm{GABA}_{\mathrm{A}} \mathrm{R} \beta 2 / 3$ was substantially increased by BDNF treatment (Fig. 5A). The data provide evidence that BDNF also affects postsynaptic components of GABAergic synapses.

\section{Brain-derived neurotrophic factor upregulates the expression of synaptic vesicle-related proteins}

The synaptic vesicle-associated proteins synaptophysin and synaptobrevin, are increased by the application of BDNF in hippocampal slice cultures (Tartaglia et al., 2001) and reduced in the hippocampal synaptosomes of BDNF knock-out mice (PozzoMiller et al., 1999). These two reports suggest that these changes are associated with the ability of transmitter release. However, in cultures of dissociated neurons we could not find an apparent increase in glutamate release (Fig. $1 A$ ). Therefore, we suspected that BDNF does not alter the expression of the presynaptic 

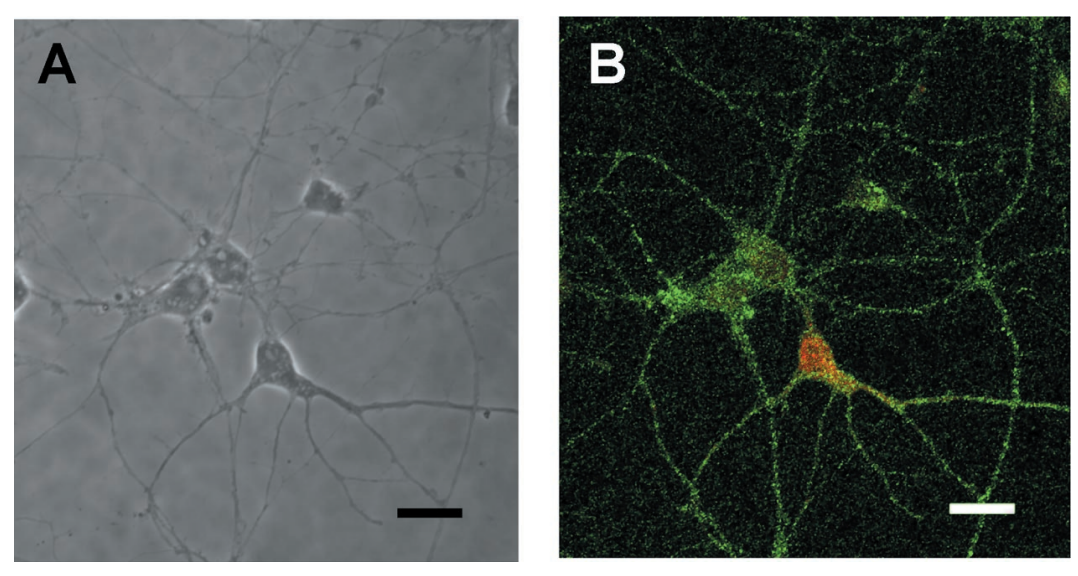

Figure 4. TrkB is expressed in both GABAergic and nonGABAergic neurons. The DIC photograph $(A)$ shows the same field as the immunocytochemical image $(B)$ for TrkB (green) and GABA (red). The immunostaining was performed at $7 \mathrm{~d}$ in vitro for cells cultured without BDNF. TrkB immunoreactivity was evident in both GABA-positive and GABA-negative cells. Similar results were obtained from four independent cultures. Scale bar, $20 \mu \mathrm{m}$.
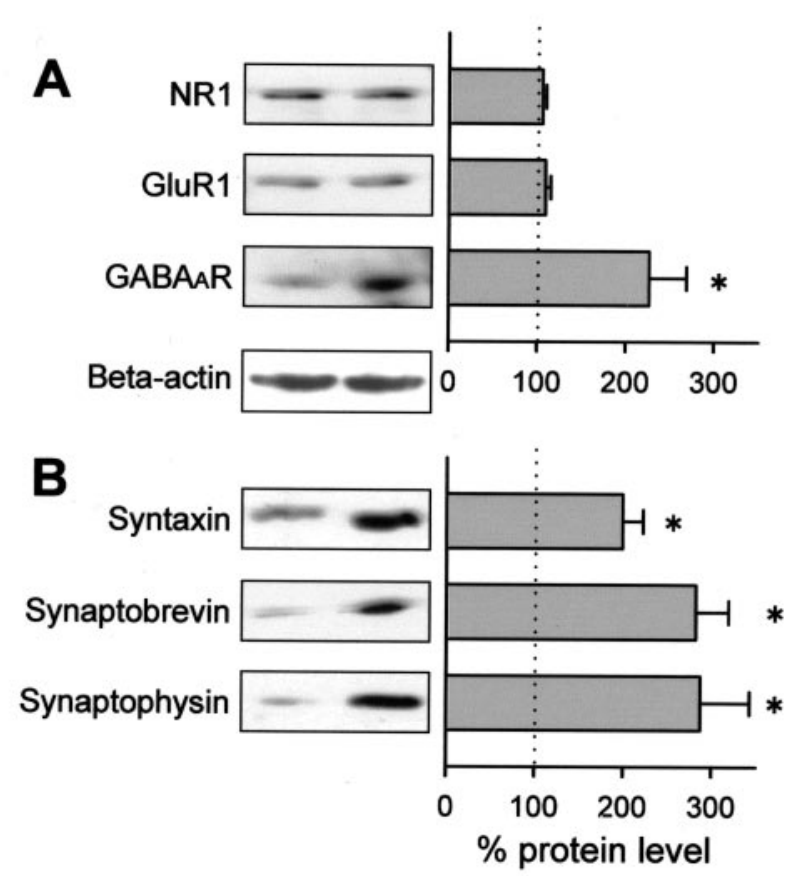

Figure 5. BDNF upregulates $\mathrm{GABA}_{\mathrm{A}}$ receptor $(G A B A A R)$ protein and presynaptic proteins. Cells were cultured in the presence or absence of 50 $\mathrm{ng} / \mathrm{ml} \mathrm{BDNF}$ for 7-10 d, and the extracts were analyzed by Western blot for NR1, GluR1, and GABA $\mathrm{R} \beta 2 / 3(A)$, and syntaxin, synaptobrevin, and synaptophysin $(B)$. Immunoreactive signals were normalized to the control. Insets are representative Western blots. A blot for $\beta$-actin for normalization is also shown. Data are means \pm SEM of three independent experiments. ${ }^{*} p<0.05$ versus control, Student's $t$ test.

proteins in our cultures. This possibility was addressed by Western blot analysis. We confirmed that BDNF produced approximately a threefold increase in synaptophysin and synaptobrevin (Fig. 5B). In addition, we found that synapsin, another presynaptic protein, was also increased approximately twofold after BDNF treatment.

These results urged us to examine the effect of BDNF on the dynamics of synaptic vesicles. The pool of synaptic vesicles can be functionally divided into two classes, i.e., recycling and resting pools (Sudhof, 2000). After exocytosis of transmitters, a synaptic vesicle in the recycling pool undergoes reuptake and is subsequently reused. The styryl dye FM1-43 is co-internalized with recycling synaptic vesicles when transmitter release occurs, and
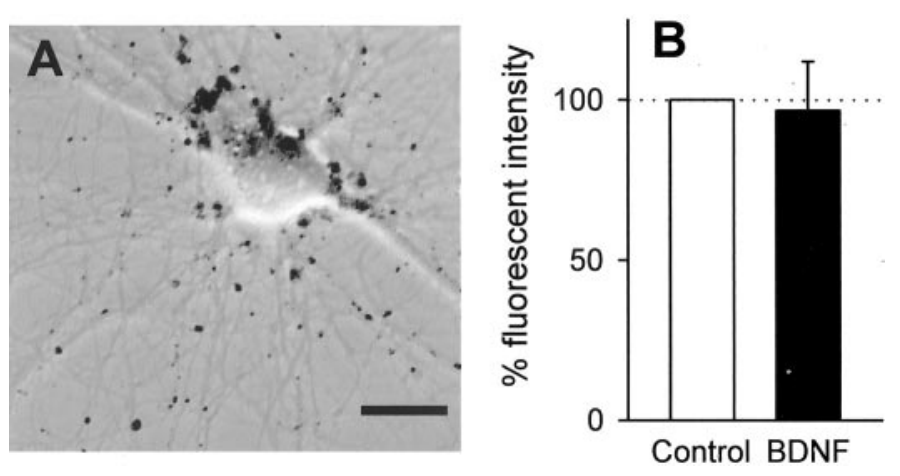

Figure 6. BDNF induces no change in the amount of synaptic vesicles in the recycling pool. $A$, Confocal FM1-43 signals are shown as black puncta superimposed on DIC image of hippocampal culture. Scale bar, $20 \mu \mathrm{m}$. B, FM1-43 fluorescence intensity in cultures exposed to $50 \mathrm{ng} / \mathrm{ml} \mathrm{BDNF}$ for $7 \mathrm{~d}$ was quantitatively analyzed. The mean fluorescence intensity of four frames per well was normalized to the control. Data are means \pm SEM of 10 wells of five independent experiments.

thus works as a good fluorescent marker of these vesicles. On the other hand, the resting pool cannot be recruited even after extensive stimulation such as $90 \mathrm{~mm} \mathrm{~K}^{+}$for $90 \mathrm{sec}$ (Harata et al., 2001). Therefore, $\mathrm{K}^{+}$depolarization for $60 \mathrm{sec}$ was used here for a specific detection of recycling vesicles.

FM1-43 fluorescent punctae were widely detected in cultures (Fig. 6A). They often overlapped each other so that we could not discriminate one from another. Thus, the mean fluorescence intensity of the whole image was adopted as an index of the total amount of recycling vesicles. There was no significant difference in signal intensity between control and BDNF-treated cultures (Fig. 6B), which suggests that BDNF does not increase the amount of recycling vesicles in the whole population of neurons.

\section{DISCUSSION}

The present work has focused on the long-term effect of BDNF on developing hippocampal neurons and has shown that BDNF promotes GABAergic maturation: long-term treatment with BDNF facilitated high $\mathrm{K}^{+}$-elicited GABA release, upregulated the expression of GAD and $\mathrm{GABA}_{\mathrm{A}}$ receptors, and enlarged the soma of GABAergic neurons.

Although the role of BDNF in CNS development has been intensively investigated, previous studies have not yet achieved a good consensus. For example, long-term exposure to BDNF is shown to increase the frequency and amplitude of miniature EPSCs (Vicario-Abejon et al., 1998; McLean et al., 2000), 
whereas other reports indicated that blockade of endogenous BDNF by TrkB-IgG induces an increase in miniature EPSC amplitude (Rutherford et al., 1998). Such an inconsistency may be derived from different experimental conditions, e.g., species, animal ages, brain regions, in vivo-in vitro, and acute or culture preparations. Even in culture conditions, experimental data are possibly affected by many experimental factors such as culture density (Ikegaya et al., 2000a), culture medium, serum (Nakagami et al., 1997; Tyler and Pozzo-Miller, 2001), and the ratio of inhibitory neurons. Secondary factors may also have a definitive influence on experimental data. For example, BDNF may indirectly affect excitatory neurons via neuropeptide Y (Greber et al., 1994; Marty et al., 1996; Reibel et al., 2001). Therefore, it is not surprising that BDNF exerts different effects in different experimental systems. Rather, it is very important to determine from among them the primary action of BDNF. The primary action must be more reliably detectable under any experimental conditions. For this purpose, simple experimental systems are useful to attain uniform and coherent conclusions under well controlled conditions, which may allow us to appreciate other data from more complex systems.

In the present study, by using a simple culture system to afford heterogeneous neural networks, we performed comprehensive analyses on neuronal properties. As a result, our observations revealed clearly that BDNF promotes GABAergic maturation even in the case of no apparent change in glutamatergic properties, suggesting that GABAergic maturation is the primary effect of BDNF. At the same time, we found that BDNF induces a twofold to threefold increase in levels of presynaptic proteins; that is, synaptophysin, synaptobrevin, and syntaxin. This intensive alteration cannot be explained merely by an increase in GABAergic synapses because GABAergic neurons were only $20 \%$ of the total neurons in our cultures. The upregulation of presynaptic proteins probably occurs in both excitatory and inhibitory neurons. Interestingly, all these proteins did not increase at an equal rate; the levels of synaptophysin and synaptobrevin were more enhanced as compared with syntaxin. Synaptobrevin and synaptophysin are both localized in the membrane of synaptic vesicles, whereas syntaxin is predominantly localized at presynaptic plasma membrane (Brunger, 2000). Therefore, a similar degree of synaptobrevin and synaptophysin may reflect an increase in the total number of synaptic vesicles. Considering a lack of the effect of BDNF on FM1-43-labeled recycling vesicles, it is possible to conclude that BDNF enlarges the resting pool of synaptic vesicles. Therefore, BDNF may also potentially promote the maturation of excitatory synapses via the enhancement of a latent capacity of neurotransmission. In contrast with studies by other groups (Narisawa-Saito et al., 1999; Collin et al., 2001; Tyler and Pozzo-Miller, 2001), we found no evidence that BDNF actually facilitates the physiological function of glutamatergic synapses. Therefore, we consider that BDNF-induced conversion of immature glutamatergic synapses into active synapses depends on additional secondary factors.

Our previous report indicated that short-term application of BDNF rapidly induces a depression of inhibitory synaptic transmissions in hippocampal slices (Tanaka et al., 1997), which may be mediated, in part, by downregulation of $\mathrm{GABA}_{\mathrm{A}}$ receptors (Brunig et al., 2001). The present study has shown the opposite, that long-term treatment with BDNF promotes the maturation of inhibitory synapses via upregulating GABA release and $\mathrm{GABA}_{\mathrm{A}}$ receptor expression. A similar BDNF-mediated maturation of inhibitory transmission was reported in the visual cortex, which is likely to play an essential role in terminating the critical period for plasticity in ocular dominance columns (Hensch et al., 1998; Huang et al., 1999). Considering that BDNF is secreted from hippocampal neurons in an activity-dependent manner (Goodmann et al., 1996), BDNF may rapidly enhance the facility of network plasticity through GABAergic disinhibition, but in the following late phase, it may serve to calm the enhanced plasticity through the enhancement of GABAergic influence. We hypothesize that this biphasic action of BDNF provides a highly adaptive mechanism to ensure flexible temporal integration of signals, which would help to etch an event that occurs during a limited period into stabilized neural circuits.

In conclusion, our findings indicate that BDNF selectively promotes GABAergic maturation at both presynaptic and postsynaptic components. This selective effect did not depend on a long-term alteration in glutamatergic properties. Therefore, we conclude that inhibitory neurons are the principal target of BDNF action. Our study may provide significant insights into functional plasticity in developing neural networks in the CNS.

\section{REFERENCES}

Binder DK, Routbort MJ, Ryan TE, Yancopoulos GD, McNamara JO (1999) Selective inhibition of kindling development by intraventricular administration of TrkB receptor body. J Neurosci 19:1424-1436.

Binder DK, Croll SD, Gall CM, Scharfman HE (2001) BDNF and epilepsy: too much of a good thing? Trends Neurosci 24:47-53.

Brunger AT (2000) Structural insights into the molecular mechanism of $\mathrm{Ca}^{2+}$-dependent exocytosis. Curr Opin Neurobiol 10:293-302.

Brunig I, Penschuck S, Berninger B, Benson J, Fritschy JM (2001) BDNF reduces miniature inhibitory postsynaptic currents by rapid downregulation of $\mathrm{GABA}_{\mathrm{A}}$ receptor surface expression. Eur J Neurosci 13:1320-1328.

Cabelli RJ, Hohn A, Shatz CJ (1995) Inhibition of ocular dominance column formation by infusion of NT-4/5 or BDNF. Science 267:1662-1666.

Collin C, Vicario-Abejon C, Rubio ME, Wenthold RJ, McKay RD, Segal M (2001) Neurotrophins act at presynaptic terminals to activate synapses among cultured hippocampal neurons. Eur J Neurosci 13:1273-1282.

Goodmann LJ, Valverde J, Lim F, Geschwind MD, Federoff HJ, Geller AI, Hefti F (1996) Regulated release and polarized localization of brain-derived neurotrophic factor in hippocampal neurons. Mol Cell Neurosci 7:222-238.

Greber S, Schwarzer C, Sperk G (1994) Neuropeptide Y inhibits potassium-stimulated glutamate release through $\mathrm{Y}_{2}$ receptors in rat hippocampal slices in vitro. Br J Pharmacol 113:737-740.

Harata N, Ryan TA, Smith SJ, Buchanan J, Tsien RW (2001) Visualizing recycling synaptic vesicles in hippocampal neurons by FM 1-43 photoconversion. Proc Natl Acad Sci USA 98:12748-12753.

Hensch TK, Fagiolini M, Mataga N, Stryker MP, Baekkeskov S, Kash SF (1998) Local GABA circuit control of experience-dependent plasticity in developing visual cortex. Science 282:1504-1508.

Huang ZJ, Kirkwood A, Pizzorusso T, Porciatti V, Morales B, Bear MF, Maffei L, Tonegawa S (1999) BDNF regulates the maturation of inhibition and the critical period of plasticity in mouse visual cortex. Cell 98:739-755.

Ikegaya Y, Itsukaichi-Nishida Y, Ishihara M, Tanaka D, Matsuki N (2000a) Distance of target search of isolated rat hippocampal neuron is about $150 \mu \mathrm{m}$. Neuroscience 97:215-217.

Ikegaya Y, Nishiyama N, Matsuki N (2000b) L-type $\mathrm{Ca}^{2+}$ channel blocker inhibits mossy fiber sprouting and cognitive deficits following pilocarpine seizures in immature mice. Neuroscience 98:647-659.

Ikegaya Y, Ishizaka Y, Matsuki N (2002) BDNF attenuates hippocampal LTD via activation of phospholipase C: implications for a vertical shift in the frequency-response curve of synaptic plasticity. Eur J Neurosci 16:145-148.

Jeftinija SD, Jeftinija KV, Stefanovic G, Liu F (1996) Neuroligandevoked calcium-dependent release of excitatory amino acids from cultured astrocytes. J Neurochem 66:676-684.

Larmet Y, Reibel S, Carnahan J, Nawa H, Marescaux C, Depaulis A (1995) Protective effects of brain-derived neurotrophic factor on the development of hippocampal kindling in the rat. NeuroReport 6:1937-1941.

Lein ES, Shatz CJ (2000) Rapid regulation of brain-derived neurotrophic factor mRNA within eye-specific circuits during ocular dominance column formation. J Neurosci 20:1470-1483. 
Lewin GR, Barde YA (1996) Physiology of neurotrophins. Annu Rev Neurosci 19:289-317.

Lindroth P, Mopper K (1979) High performance liquid chromatographic determination of subpicomole amounts of amino acids by precolumn fluorescence derivatization with $o$-phthalaldehyde. Anal Chem $51: 1667-1674$.

Lowenstein DH, Arenault L (1996) The effects of growth factors on the survival and differentiation of cultured dentate gyrus. J Neurosci $16: 142-144$.

Lu B, Figurov A (1997) Role of neurotrophins in synapse development and plasticity. Rev Neurosci 8:1-12.

Marty S, Berninger B, Carroll P, Thoenen H (1996) GABAergic stimulation regulates the phenotype of hippocampal interneurons through the regulation of brain-derived neurotrophic factor. Neuron 16:565-570.

Mataga N, Fujishima S, Condie BG, Hensch TK (2001) Experiencedependent plasticity of mouse visual cortex in the absence of the neuronal activity-dependent marker egr1/zif268. J Neurosci 21:97249732 .

McLean BM, Pittman AJ, Lo DC (2000) Brain-derived neurotrophic factor differentially regulates excitatory and inhibitory synaptic transmission in hippocampal cultures. J Neurosci 20:3221-3232.

Nakagami Y, Saito H, Matsuki N (1997) Basic fibroblast growth factor and brain-derived neurotrophic factor promote survival and neuronal circuit formation in organotypic hippocampal culture. Jpn J Pharmacol 75:319-326.

Narisawa-Saito M, Carnahan J, Araki K, Yamaguchi T, Nawa H (1999) Brain-derived neurotrophic factor regulates the expression of AMPA receptor proteins in neocortical neurons. Neuroscience 88:1009-1014.

Pozzo-Miller LD, Gottschalk W, Zhang L, McDermott K, Du J, Gopalakrishnan R, Oho C, Sheng ZH, Lu B (1999) Impairments in high-frequency transmission, synaptic vesicle docking, and synaptic protein distribution in the hippocampus of BDNF knockout mice. J Neurosci 19:4972-4983.

Reibel S, Depaulis A, Larmet Y (2001) BDNF and epilepsy-the bad could turn out to be good. Trends Neurosci 24:318-319.

Renger JJ, Hartman KN, Tsuchimoto Y, Yokoi M, Nakanishi S, Hensch
TK (2002) Experience-dependent plasticity without long-term depression by type 2 metabotropic glutamate receptors in developing visual cortex. Proc Natl Acad Sci USA 99:1041-1046.

Rutherford LC, Nelson SB, Turrigiano GG (1998) BDNF has opposite effects on the quantal amplitude of pyramidal neuron and interneuron excitatory synapses. Neuron 21:521-530.

Sato S, Burgess SB, McIlwain DL (1994) Transcription and motoneuron size. J Neurochem 63:1609-1615.

Schmidt EE, Schibler U (1995) Cell size regulation, a mechanism that controls cellular RNA accumulation: consequences on regulation of the ubiquitous transcription factors Oct1 and NF-Y, and the liver-enriched transcription factor DBP. J Cell Biol 128:467-483.

Shitaka Y, Matsuki N, Saito H, Katsuki H (1996) Basic fibroblast growth factor increases functional L-type $\mathrm{Ca}^{2+}$ channels in fetal rat hippocampal neurons: implications for neurite morphogenesis in vitro. J Neurosci 16:6476-6489.

Sudhof TC (2000) The synaptic vesicle cycle revisited. Neuron 28:317-320.

Tanaka T, Saito H, Matsuki N (1997) Inhibition of $\mathrm{GABA}_{A}$ synaptic responses by brain-derived neurotrophic factor (BDNF) in rat hippocampus. J Neurosci 17:2959-2966.

Tartaglia N, Du J, Tyler WJ, Neale E, Pozzo-Miller L, Lu B (2001) Protein synthesis-dependent and -independent regulation of hippocampal synapses by brain-derived neurotrophic factor. J Biol Chem 276:37585-37593.

Thoenen H (1995) Neurotrophins and neuronal plasticity. Science 270:593-598.

Tyler WJ, Pozzo-Miller LD (2001) BDNF enhances quantal neurotransmitter release and increases the number of docked vesicles at the active zones of hippocampal excitatory synapses. J Neurosci 21:4249-4258

Vicario-Abejon C, Collin C, McKay RD, Segal M (1998) Neurotrophins induce formation of functional excitatory and inhibitory synapses between cultured hippocampal neurons. J Neurosci 18:7256-7271.

Vicario-Abejon C, Collin C, Tsoulfas P, McKay RD (2000) Hippocampal stem cells differentiate into excitatory and inhibitory neurons. Eur J Neurosci 12:677-688. 